\title{
Modeling of Small Wind Turbines based on PMSG with Diode Bridge for Sensorless Maximum Power Tracking
}

Authors: Andoni Urtasun, Pablo Sanchis, Idoia San Martín, Jesús López, and Luis Marroyo

The authors are from the Department of Electrical and Electronic Engineering, Public University of Navarra, Pamplona 31006, Spain (e-mail: andoni.urtasun@unavarra.es; pablo.sanchis@unavarra.es;_idoia.sanmartin@unavarra.es;_jesus.lopez@unavarra.es; luisma@unavarra.es).

Corresponding author: Andoni Urtasun, address: C/Arrosadia s/n, Planta Baja, 31006 (Pamplona, Spain), email: andoni.urtasun@unavarra.es, phone number: 0034948168934.

Abstract: The Permanent Magnet Synchronous Generator (PMSG) with diode bridge is frequently used in small Wind Energy Conversion Systems (WECS). This configuration is robust and cheap, and therefore suitable for small WECS. In order to achieve Maximum Power Point Tracking (MPPT) with no mechanical sensors, it is possible to impose the relationship between the DC voltage and the DC current on the optimum operating points. However, this relationship is difficult to calculate theoretically since the whole system is involved. In fact, as there is no model of the whole system in the literature, the optimum curve $I_{L}{ }^{*}\left(V_{d c}\right)$ is obtained with experimental tests or simulations. This paper develops an accurate model of the whole WECS, thereby making it possible to relate the electrical variables to the mechanical ones. With this model, it is possible to calculate the optimum curve $I_{L}{ }^{*}\left(V_{d c}\right)$ from commonly-known system parameters and to control the system from the DC side. Experimental results validate the theoretical analysis and show that maximum power is extracted for actual wind speed profiles.

Keywords: Boost converter, diode bridge, MPPT, PMSG, sensorless control, variable speed wind generation. 


\section{INTRODUCTION}

Among all renewable resources, wind is one of the most accessible. In addition, thanks to technological advances, its costs are continuously being reduced (4 cents $/ \mathrm{kWh}$ ), making it competitive against other energy sources [1]. As a result, the global wind power capacity is rapidly increasing. The wind energy utilization ratio has shown an average growth rate of $30 \%$ over the last 15 years. Furthermore, the installed global cumulative wind power capacity increased to $197 \mathrm{GW}$ in 2010 compared to around $6.1 \mathrm{GW}$ in 1996 [2].

With regard to small wind turbines, 21,000 units were installed in 2009, representing a global power capacity of $42.5 \mathrm{MW}$ and a $10 \%$ growth over 2008 [3]. For small wind generation (less than $100 \mathrm{~kW}$ ), a Permanent Magnet Synchronous Generator (PMSG) is preferred because of its reliability, high efficiency and low cost. Two configurations are currently in major use with this machine [4, 5], as shown in Fig. 1.

In the first configuration (Fig. 1(a)), the PMSG is driven by an active rectifier, followed by the DC bus capacitor. A vector control is carried out where the generator torque is controlled by means of the quadrature current $i_{q}$ and the losses are minimized by the direct current $i_{d}[6]$. This enables improved control and higher efficiency $[4,6]$.

In the second alternative (Fig. 1(b)), the PMSG is followed by a diode bridge, a boost converter (which could also be either a buck or buck-boost converter) and the DC bus capacitor. Since reactive power is not indispensable for the PMSG operation, this direct connection to a diode bridge is possible. The torque can be controlled by means of the voltage or current at the diode bridge output $[7,8]$. With this configuration, the PMSG efficiency is lower and more harmonics are generated. However, robustness, simplicity of control and conversion efficiency, all of which are essential features in small wind turbines, are substantially improved and the costs are lowered [5].

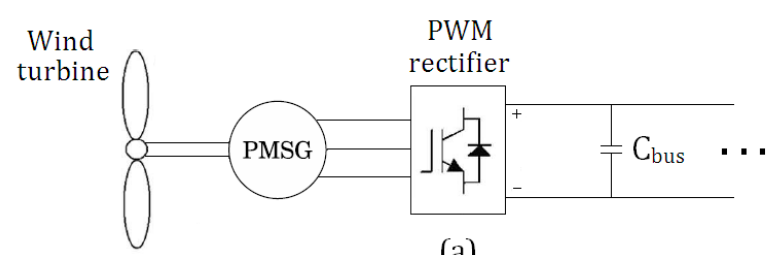

(a)

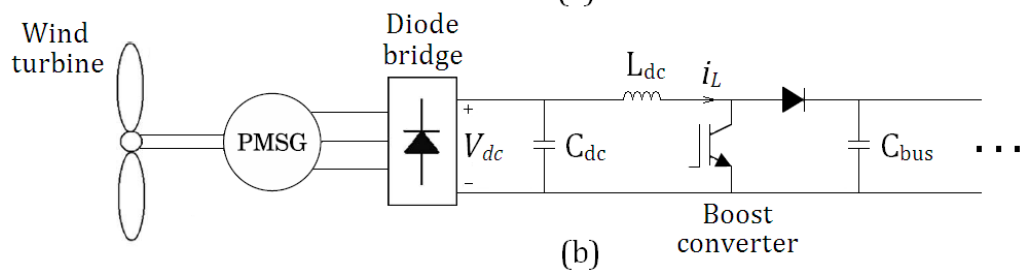

Fig. 1. Wind turbine system: active/passive rectifier.

Without measuring the wind speed, two different methods for Maximum Power Point Tracking (MPPT) are usual for this second configuration. If the characteristics of the system are unknown, the perturbation and observation $(\mathrm{P} \& \mathrm{O})$ strategy might be used [7, 9-12]. The problem with this strategy is that larger power variations are often caused by wind changes, which can be misinterpreted by the MPPT strategy. This can drive the system off, resulting in a poor MPPT $[13,14]$.

The second strategy makes the system operate based on a pre-obtained system curve. Normally, the optimum curve $P^{*}(\omega)$ is used $[15,16]$. The problem of this optimum curve is that a shaft speed sensor is required. This is also the case if the curve $V_{d c}{ }^{*}(\omega)$ is used [17].

Some authors have realized that the MPPT can be achieved using only the DC variables. As a result, alternative optimum curves have been proposed in other works, such as $V_{d c}{ }^{*}\left(P_{d c}\right)[18,19]$ and $I_{L}{ }^{*}\left(V_{d c}\right)$ [1], having similar characteristics and not requiring a mechanical speed sensor. 
However, since the whole system is involved, these curves are more complicated to calculate theoretically. Consequently, up to now, they have been calculated using an interpolation based on optimum points obtained by sweeping, either experimentally [1, 19], or by simulation [18], the complete output power curves for different wind speeds,

In order to avoid sweeping the power curve, a model of the WECS, relating the electrical variables to the mechanical ones, must be used. However, there is no model of the whole system in the literature. Although its different subsystems have been analyzed separately, they have never been considered as a whole. Regarding the "PMSG + diode bridge" subsystem, many models have been developed without considering the losses [20, 21]. However, in small wind applications, the power and the speed are low and the line can be very long. As a result, the copper losses cannot be neglected and these models lead to major errors [13].

This paper presents a theoretical analysis of the whole system, which makes it possible to relate the DC electrical variables to the mechanical variables of the turbine. Firstly, a more accurate model of the "PMSG + diode bridge" which accounts for the generator and line losses is developed. Then, based on this model, a model for the whole system is obtained. This study is very useful to understand the system operation. Furthermore, it makes it possible to obtain an accurate optimum curve $I_{L}{ }^{*}\left(V_{d c}\right)$ from known system parameters, thereby avoiding the need for experimental tests or simulations. Based on this curve, the system is easily controlled from the DC side and the MPPT is optimized for the entire operating range.

\section{INTERACTION BETWEEN SUBSYSTEMS}

The WECS studied in this work is shown in Fig. 2. The behavior of this system can be defined by the wind speed $v_{w}$ and three internal variables: the mechanical speed $\omega_{m}$, the diode bridge output voltage $V_{d c}$ and the inductor current $I_{L}$. Three subsystems will be distinguished, where the behavior of each subsystem is defined by two of these variables:

- The wind turbine $\left(v_{w}\right.$ and $\left.\omega_{m}\right)$.

- The PMSG with diode bridge ( $\omega_{m}$ and $V_{d c}$ ).

- The boost converter $\left(V_{d c}\right.$ and $\left.I_{L}\right)$.

With regard to Fig. 2, the power $P_{T}\left(v_{w}, \omega_{m}\right)$ represents the power captured by the wind turbine once the friction losses have been deducted. Part of this power is absorbed by the PMSG, and the remainder changes the shaft speed $\left(P_{J}\right)$. The power entering the PMSG is its electromagnetic power $P_{e m}\left(\omega_{m}, V_{d c}\right)$. Neglecting the magnetic losses of the machine and the diode losses of the bridge, the electromagnetic power $P_{e m}\left(\omega_{m}, V_{d c}\right)$ is divided into the resistive losses caused by the PMSG and the line, $P_{R}\left(\omega_{m}, V_{d c}\right)$, and the diode bridge output power, $P_{0}\left(\omega_{m}, V_{d c}\right)$. Finally, most of the $P_{0}\left(\omega_{m}, V_{d c}\right)$ enters the boost converter, $P_{L}\left(V_{d c}, I_{L}\right)$, and the remainder goes to change the $C_{d c}$ capacitor voltage $\left(P_{C}\right)$.

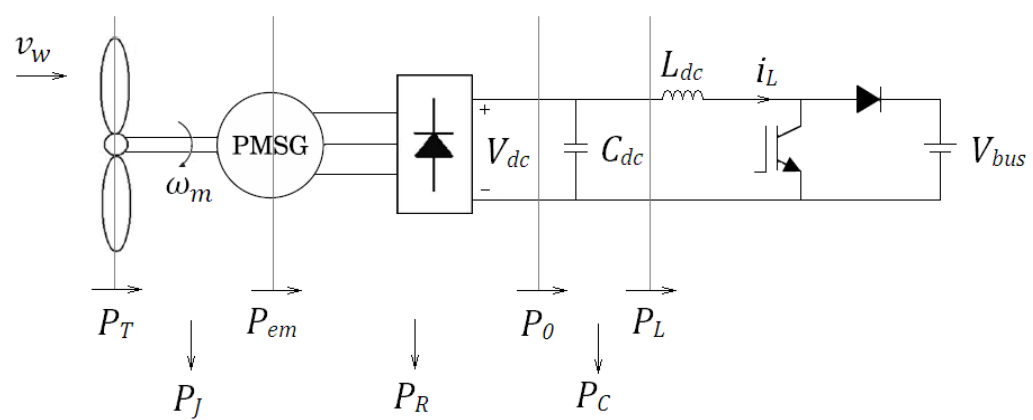

Fig. 2. Global system and power balance. 
This power balance only accounts for the slowest dynamics, namely the mechanical inertia and the $C_{d c}$ capacitor. It is expressed as:

$$
\begin{aligned}
& P_{T}\left(v_{w}, \omega_{m}\right)-P_{e m}\left(\omega_{m}, V_{d c}\right)=J \omega_{m} \frac{d \omega_{m}}{d t} \\
& P_{e m}\left(\omega_{m}, V_{d c}\right)-P_{R}\left(\omega_{m}, V_{d c}\right)=P_{0}\left(\omega_{m}, V_{d c}\right) \\
& P_{0}\left(\omega_{m}, V_{d c}\right)-P_{L}\left(V_{d c}, I_{L}\right)=C_{d c} V_{d c} \frac{d V_{d c}}{d t}
\end{aligned}
$$

where $J$ is the total inertia moment of both the wind turbine and the PMSG.

In steady-state operation, (1) and (3) become:

$$
\begin{aligned}
& P_{T}\left(v_{w}, \omega_{m}\right)=P_{e m}\left(\omega_{m}, V_{d c}\right) \\
& P_{0}\left(\omega_{m}, V_{d c}\right)=P_{L}\left(V_{d c}, I_{L}\right)
\end{aligned}
$$

The model of the PMSG connected to a diode bridge will first be studied in section 3 . With this model, accurate expressions for the electromagnetic power $P_{e m}\left(\omega_{m}, V_{d c}\right)$ and the diode bridge output power $P_{0}\left(\omega_{m}, V_{d c}\right)$ will be obtained. This will make it possible to consider the "PMSG + diode bridge" configuration as a single subsystem, with the input and output powers being calculated as a function of the mechanical speed $\omega_{m}$ and the output voltage $V_{d c}$.

Then, in section 4, the wind turbine will be integrated into the "PMSG + diode bridge". For this purpose, the power $P_{e m}\left(\omega_{m}, V_{d c}\right)$ and the power captured by the turbine $P_{T}\left(v_{w}, \omega_{m}\right)$ will be related making use of (1) in dynamic operation or (4) in steady-state operation.

Finally, in section 5 , the boost converter will be incorporated in order to obtain the global model. With this aim, the power $P_{0}\left(\omega_{m}, V_{d c}\right)$ and the power that enters the boost converter $P_{L}\left(V_{d c}, I_{L}\right)$ will be related making use of (3) in dynamic operation or (5) in steady-state operation.

The modeling developed throughout this paper is applied to an actual wind turbine installed at the campus of the Public University of Navarra in Pamplona, Spain. The features of the wind turbine are compiled in Table 1 and the specifications of the PMSG and the line are compiled in Table 2.

\begin{tabular}{|c|c|}
\hline Nominal power & $4200 \mathrm{~W}$ \\
\hline Wind speed for turn on & $3.5 \mathrm{~m} / \mathrm{s}$ \\
\hline Wind speed for nominal power & $12 \mathrm{~m} / \mathrm{s}$ \\
\hline Optimum power coefficient & 0.316 \\
\hline Optimum tip speed ratio & 8.63 \\
\hline Diameter of the rotor & $4 \mathrm{~m}$ \\
\hline Inertia & $5 \mathrm{~kg} \cdot \mathrm{m}^{2}$ \\
\hline Height of the nacelle & $23 \mathrm{~m}$ \\
\hline
\end{tabular}

Table 1. Features of the wind turbine placed in the campus of the Public University of Navarre (Pamplona, Spain)

\begin{tabular}{|c|c|}
\hline Nominal speed & $600 \mathrm{rpm}$ \\
\hline Line voltage constant & $475 \mathrm{~V} / \mathrm{krpm}$ \\
\hline Nominal current & $11.6 \mathrm{~A}$ \\
\hline Number of pole pairs & 15 pairs \\
\hline Stator equivalent resistance & $0.6 \Omega$ \\
\hline Stator equivalent inductance & $4.9 \mathrm{mH}$ \\
\hline Line resistance & $0.2 \Omega$ \\
\hline Line inductance & $0.3 \mathrm{mH}$ \\
\hline
\end{tabular}

Table 2. Specifications of the PMSG and the line 


\section{PMSG WITH DIODE BRIDGE}

\subsection{System Description}

The equivalent circuit of a PMSG connected to a diode bridge at steady-state operation is shown in Fig. 3, where $R$ and $L$ include the resistance and inductance of the PMSG, the line, and the possible transformer; $e_{a}, e_{b}$ and $e_{c}$ are the induced electromotive forces; $i_{a}, i_{b}$ and $i_{c}$ are the phase currents; $i_{d c}$ is the diode bridge output current; and $V_{d c}$ is the diode bridge output voltage.

The electrical system, represented by Fig. 3, is related to the mechanical system by:

$$
\begin{gathered}
e_{a}=\sqrt{2} E \sin (\theta) \\
e_{b}=\sqrt{2} E \sin (\theta-2 \pi / 3) \\
e_{c}=\sqrt{2} E \sin (\theta+2 \pi / 3) \\
E=k \cdot \omega \\
\theta=\omega \cdot t \\
\omega=p \cdot \omega_{m}
\end{gathered}
$$

where $E$ is the RMS value of the induced electromotive force, $\theta$ is the electrical angle, $k$ is the PMSG voltage constant, $\omega$ is the electrical speed, $p$ is the number of pole pairs, and $\omega_{m}$ is the mechanical speed.

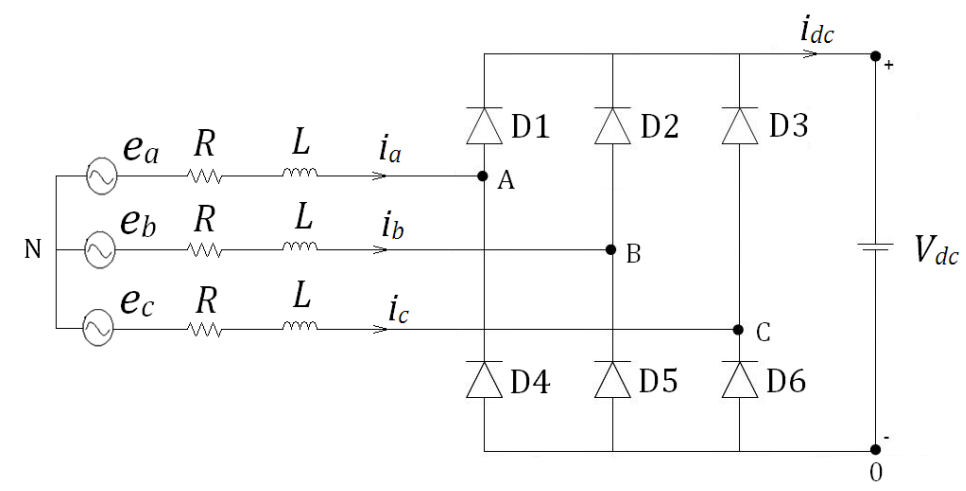

Fig. 3. Equivalent circuit of a PMSG connected to a diode bridge at steady-state.

Operating at steady-state and given that the $C_{d c}$ capacitor and the system inertia are high enough to neglect the ripple, the voltage $V_{d c}$ and the speeds $\omega$ and $\omega_{m}$ can be considered as constant. Depending on the value of $\omega_{m}$ and $V_{d c}$, the phase current will be either continuous or discontinuous, resulting in different expressions for powers. Since the system is balanced, only phase $\mathrm{A}$ is henceforth studied.

\subsection{Continuous Conduction Mode (CCM)}

For high voltage $E$ or low voltage $V_{d c}$ the current is continuous (the exact relationship for the boundary will be obtained in section 3.4). Thus, each diode conducts for $\pi$ radians: D1 while the current of phase $\mathrm{A}$ is positive and $\mathrm{D} 4$ while it is negative.

The voltage $v_{A N}$ can be defined as a function of the conducting diodes:

$$
v_{A N}=\left(2 u_{1}-u_{2}-u_{3}\right) \cdot V_{d c} / 3
$$

where $u_{1}, u_{2}$ and $u_{3}$ are the connection functions of D1, D2 and D3, respectively (1 while conducting and 0 while being switched off). 
Fig. 4 shows voltages $e_{a}$ and $v_{A N}$ and currents $i_{a}, i_{b}, i_{c}$ and $i_{d c}$. Considering the sign of the currents and (12), the current $i_{a}$ and the voltage $v_{A N}$ are in phase. Furthermore, since the diode bridge does not exchange reactive power, the PMSG must provide its own reactive power, resulting in the lag angle $\varphi$ between $e_{a}$ and $i_{a}$ shown in Fig. 4. According to the commutations, six intervals are defined in a period. In the subsequent paragraphs, the expressions for the current and the output and input powers are determined.
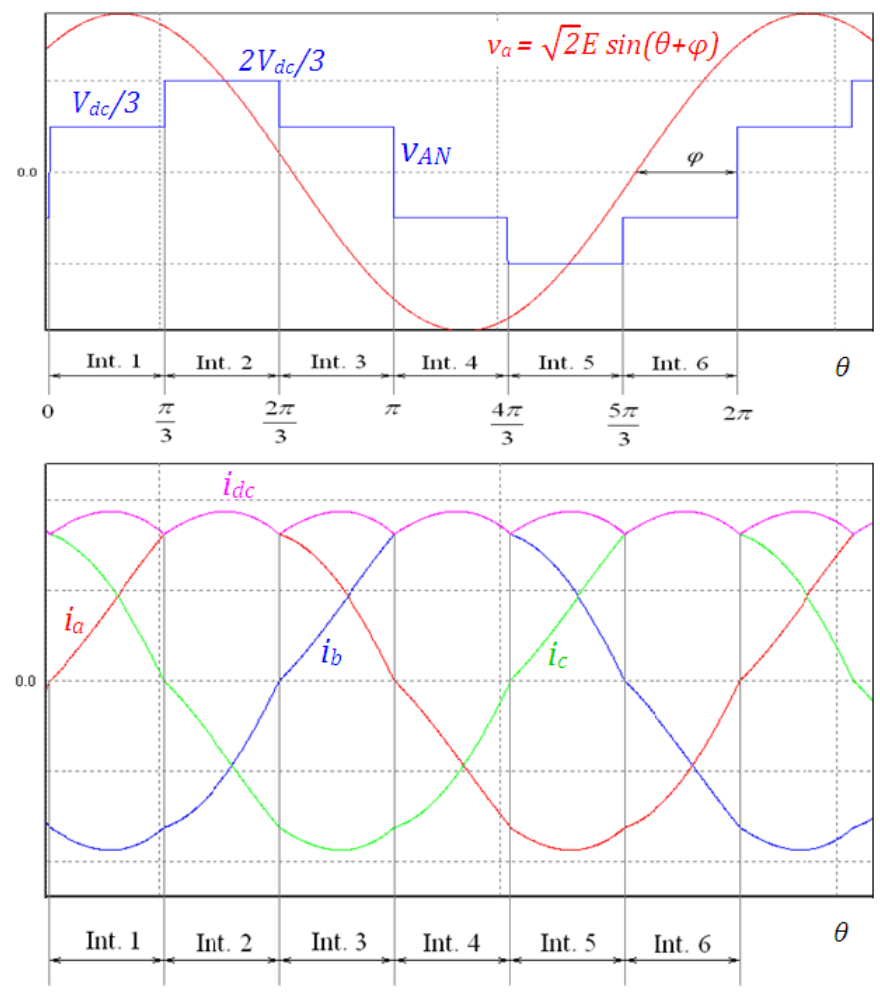

Fig. 4. Waves for continuous conduction mode.

\subsubsection{Phase Currents}

The current $i_{a}$ can be deduced from a simple RL circuit with two voltage sources, namely voltages $e_{a}$ and $v_{A N}$, as shown in Fig. 5. To simplify the notation throughout the paper, the magnitude, phase and quality factor of the impedance as well as other parameters are introduced:

$$
\begin{aligned}
Z=\sqrt{R^{2}+(\omega L)^{2}}, \quad \varphi_{Z}=\tan ^{-1}(\omega L / R), \quad Q=\omega L / R \\
e 1=\exp \left(-\frac{1}{Q} \frac{\pi}{3}\right), \quad e 2=\exp \left(-\frac{1}{Q} \frac{2 \pi}{3}\right), \quad e 3=\exp \left(-\frac{1}{Q} \pi\right) \\
e a u x=\frac{1+e 1-e 2-e 3}{1+e 3} \\
b=\sin \left(\varphi-\varphi_{Z}\right) \\
c=\cos \left(\varphi-\varphi_{Z}\right)
\end{aligned}
$$

The differential equation for the current $i_{a}$ is expressed as follows:

$$
\omega L \frac{d i_{a}}{d \theta}+R \cdot i_{a}=e_{a}-v_{A N}, \quad i_{a}(\theta=0)=0
$$


The resolution of this equation is developed in Appendix A. Then, thanks to the condition $i_{a}(\theta=\pi)=0$, the angle $\varphi$ is calculated, as also shown in Appendix A. As a result, $i_{a}$ is defined at any time as a function of the shaft speed $\omega_{m}$ and the capacitor voltage $V_{d c}$ at steady-state operation.

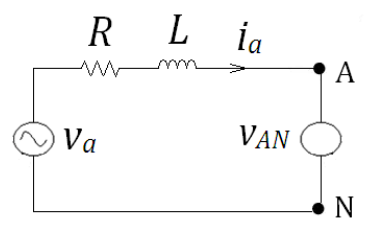

Fig. 5. Equivalent circuit for current calculation.

\subsubsection{Electromagnetic Power $P_{\text {em }}$}

Given that the active component of the fundamental harmonic of the phase current $I_{a d}$ is the only one to contribute to the active power, $P_{e m}$ can be calculated as follows:

$$
P_{e m}=3 \cdot E \cdot I_{a d}
$$

Using the Fourier analysis:

$$
I_{a d}=\frac{1}{\sqrt{2}} \cdot \frac{2}{\pi} \cdot \int_{0}^{\pi} i_{a}(\theta) \sin (\theta+\varphi) d \theta
$$

By means of (19), (20) and the expression for the current $i_{a}$, an expression for the electromagnetic power $P_{e m}\left(\omega_{m}, V_{d c}\right)$ in CCM is obtained as a function of the shaft speed $\omega_{m}$ and the capacitor voltage $V_{d c}$ :

$$
\begin{gathered}
P_{e m}=\frac{6 E^{2}}{\pi Z}\left[\frac{\pi}{2} \cdot \frac{R}{Z}-\frac{b \cdot Q \cdot(1+e 3)}{Q^{2}+1} \cdot(Q \cdot \cos \varphi+\sin \varphi)\right]- \\
-\frac{\sqrt{2} E \cdot V_{d c}}{\pi R}\left[3 \cos \varphi+\frac{Q \cdot(-2+e 1-e 2-e 3)}{Q^{2}+1} \cdot(Q \cdot \cos \varphi+\sin \varphi)\right]
\end{gathered}
$$

\subsubsection{Output power $P_{0}$}

The current $i_{a}$ coincides with the output current $i_{d c}$ in interval 2, where D1 is conducting and D2 and D3 are switched off (see Fig. 4). The ripple of $i_{d c}$ has a $6 \omega$ angular frequency. Thus, the output power $P_{0}$ is given by:

$$
P_{0}=V_{d c} \cdot I_{d c}=V_{d c} \cdot \frac{3}{\pi} \cdot \int_{\frac{\pi}{3}}^{\frac{2 \pi}{3}} i_{a}(\theta) d \theta
$$

where $I_{d c}$ is the average value of $i_{d c}$.

Using (22) and the expression for the current $i_{a}$, an expression for the diode bridge output power $P_{0}\left(\omega_{m}, V_{d c}\right)$ in CCM is obtained as a function of the shaft speed $\omega_{m}$ and the capacitor voltage $V_{d c}$ :

$$
P_{0}=\frac{3 \sqrt{2} E}{\pi Z} \cdot V_{d c} \cdot[c-b \cdot Q \cdot(e 1-e 2)]-\frac{V_{d c}^{2}}{\pi R} \cdot\left[\frac{2 \pi}{3}-Q \cdot(1-e 2)\right]
$$




\subsection{Discontinuous conduction mode (DCM)}

For low voltage $E$ or high voltage $V_{d c}$ the current is discontinuous (the exact relationship for the boundary will be obtained in section 3.4). There is a retard angle $\alpha$ for each diode during which the expression (12) is no longer valid. Instead, the fact that the current is zero in one of the phases can be taken into account to calculate the voltage $v_{A N}$. Because of the discontinuous conduction, and contrary to the three intervals defined in CCM, six intervals are identified in a semi-period. The evolution of $v_{A N}$ and the six intervals are shown in Fig. 6. The voltage $e_{a}$ and currents $i_{a}, i_{b}, i_{c}$ and $i_{d c}$ are also illustrated.
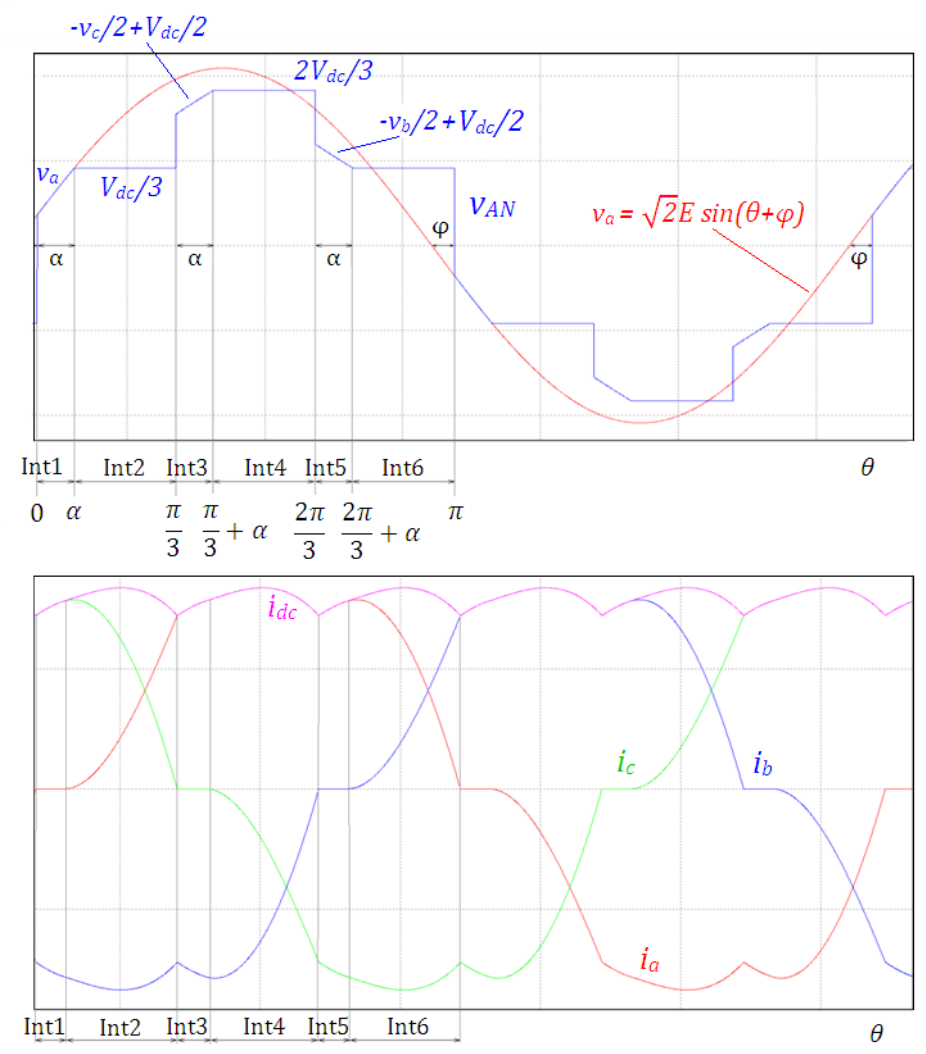

Fig. 6. Waves for discontinuous conduction mode.

During interval 1:

$$
\begin{gathered}
e_{a}=v_{A N}, \quad v_{B 0}=0, \quad v_{C 0}=V_{d c} \\
v_{A 0}=\frac{3 e_{a}+v_{B 0}+v_{C 0}}{2}=\frac{3 e_{a}+V_{d c}}{2} \\
v_{A N}=e_{a}, \quad v_{B N}=-e_{a} / 2-V_{d c} / 2, \quad v_{C N}=-e_{a} / 2+V_{d c} / 2
\end{gathered}
$$

The same considerations are taken for intervals 3 and 5. In this way, the expression for $v_{A N}$ is finally obtained (Fig. 6), but the complete calculation is not shown for reasons of space. Then, the expressions for the current and output and input powers are determined in the same way as for the CCM. Although three cases of DCM can be distinguished [20], only the case which is closer to the CCM is analyzed for the purposes of this paper.

\subsubsection{Phase Currents}

As in the continuous conduction mode (Fig. 5), the current $i_{a}$ can be obtained from an RL circuit. To simplify the notation, some parameters are also defined in this case: 


$$
\begin{gathered}
e \alpha=\exp (-\alpha / Q) \\
a=\sin \left(\alpha+\varphi-\varphi_{Z}\right), \quad d=\cos \left(\alpha+\varphi-\varphi_{Z}\right)
\end{gathered}
$$

The differential equation for the current $i_{a}$ in DCM is (18), the same as in CCM. However, the voltage $v_{A N}$ is different, as was shown in Fig. 6 . The resolution of this equation is developed in Appendix B. Then, thanks to the condition $i_{a}(\theta=\pi)=0$ and $e_{a}(\theta=\alpha)=V_{d c} / 3$, the angles $\varphi$ and $\alpha$ are calculated, as also shown in Appendix B. Hence, $i_{a}$ is defined at any time as a function of the shaft speed $\omega_{m}$ and the capacitor voltage $V_{d c}$ at steady-state operation.

\subsubsection{Electromagnetic Power $P_{e m}$}

As in CCM, the electromagnetic power $P_{e m}$ can be obtained by means of (19) and (20). Considering the expression for the current $i_{a}$, an expression for the electromagnetic power $P_{e m}\left(\omega_{m}, V_{d c}\right)$ in DCM is obtained as a function of the shaft speed $\omega_{m}$ and the capacitor voltage $V_{d c}$ :

$$
\begin{gathered}
P_{e m}=\frac{3 E^{2}}{\pi Z}\left\{\left(\pi-\frac{3 \alpha}{2}\right) \frac{R}{Z}-\frac{3}{4} \sin \left(2 \varphi-\varphi_{Z}\right)+\frac{3}{4} \sin \left(2 \varphi+2 \alpha-\varphi_{Z}\right)+\right. \\
+\frac{Q}{Q^{2}+1}\left[\left(b+a \frac{e 1}{e \alpha}-b \cdot e 1-a \frac{e 2}{e \alpha}+b \cdot e 2-2 a \frac{e 3}{e \alpha}\right) \cdot(Q \cos \varphi+\sin \varphi)-\right. \\
-3 a(Q \cos (\varphi+\alpha)+\sin (\varphi+\alpha))]\}+\frac{\sqrt{2} E}{2 \pi R} V_{d c}\{-3 \cos \varphi-3 \cos (\varphi+\alpha)+ \\
+\frac{Q}{Q^{2}+1}\left[\left(1-\frac{e 1}{e \alpha}-e 1+\frac{e 2}{e \alpha}+e 2+2 \frac{e 3}{e \alpha}\right) \cdot(Q \cos \varphi+\sin \varphi)+\right. \\
+3(Q \cos (\varphi+\alpha)+\sin (\varphi+\alpha))]\}
\end{gathered}
$$

\subsubsection{Output Power $P_{0}$}

Making use of (22), the output power $P_{0}$ can be obtained. Considering the expression for the current $i_{a}$, an expression for the diode bridge output power $P_{0}\left(\omega_{m}, V_{d c}\right)$ in DCM is obtained as a function of the speed $\omega_{m}$ and the voltage $V_{d c}$ :

$$
\begin{gathered}
P_{0}=\frac{3 \sqrt{2} E}{2 \pi Z} Q \cdot V_{d c}\left(\frac{c+d}{Q}-a+b-a \frac{e 1}{e \alpha}-b \cdot e 1+2 a \frac{e 2}{e \alpha}\right)+ \\
+\frac{V_{d c}^{2}}{2 \pi R} Q \cdot\left(\frac{\alpha-4 \pi / 3}{Q}+2+\frac{e 1}{e \alpha}-e 1-2 \frac{e 2}{e \alpha}\right)
\end{gathered}
$$

\subsection{Boundaries between Modes of Conduction}

The expressions for the powers $P_{e m}\left(\omega_{m}, V_{d c}\right)$ and $P_{0}\left(\omega_{m}, V_{d c}\right)$ have been obtained for CCM and DCM. Now, in order to choose the corresponding expression, the mode of conduction must be known. For this purpose, an expression for the boundary between modes of conduction is obtained below.

As the angle $\varphi$ in Fig. 4 gets smaller, the voltage $e_{a}$ at $\theta=0$ decreases. The value of $e_{a}$ below which the diode $\mathrm{D} 1$ does not start conducting at $\theta=0$ represents the beginning of the discontinuous conduction mode. This value is given by: 


$$
e_{a}(\theta=0)=\sqrt{2} E \sin \varphi=V_{d c} / 3
$$

With (31) and the expression of $\varphi\left(\omega, V_{d c}\right)$ obtained in CCM after applying the condition $i_{a}(\theta=\pi)=0$ and shown in Appendix A, a relationship between $V_{d c}$ and $\omega$ can be determined for the boundary between CCM and DCM:

$$
V_{d c}=3 \sqrt{2} E \frac{\omega L \cdot R}{Z \sqrt{R^{2}(1+e a u x)^{2}+(\omega L)^{2} e a u x^{2}}}
$$

where $E, Z$ and eaux depend on $\omega$. This curve is practically linear, which was expected since the electromotive force $E$ is proportional to $\omega$.

The boundary between the DCM and the non-conduction mode (NCM) is defined by the following well-known relationship:

$$
V_{d c}=\sqrt{6} \cdot E
$$

The three conduction modes and the boundaries are represented in Fig. 7.

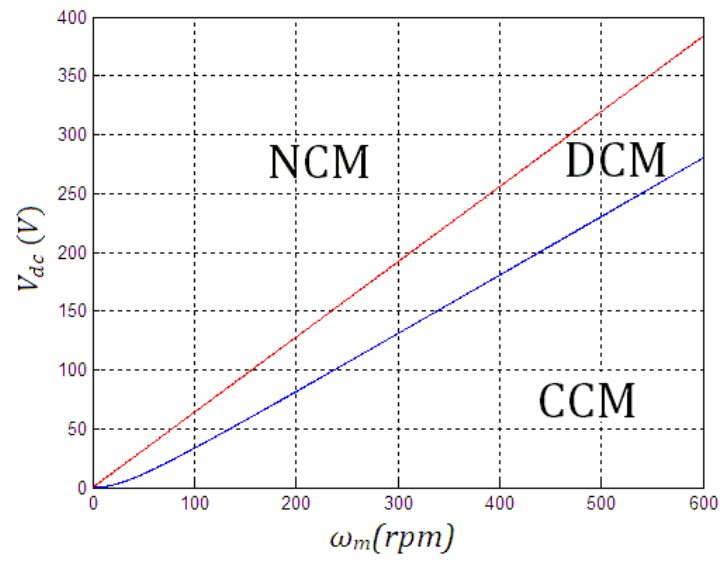

Fig. 7. Boundaries between conduction modes.

\section{INTEGRATION OF THE WIND TURBINE}

The power captured by a wind turbine using a fixed pitch depends on the wind and turbine speeds through the following well-known expression (although the friction losses will be considered later on, they are not taken into account here in order to make the analysis clearer):

$$
P_{T}=\frac{1}{2} \rho \cdot S \cdot v_{w}^{3} \cdot C_{P}(\lambda)
$$

where $\rho$ is the air density, $S$ is the wind turbine rotor swept area and $C_{P}$ is the power coefficient. In turn, the power coefficient is a function of tip speed ratio, $\lambda$, and represents the wind turbine characteristics. The tip speed ratio is given by:

$$
\lambda=\frac{R_{T} \cdot \omega_{m}}{v_{w}}
$$

where $R_{T}$ is the radius of the rotor. 
At a certain wind speed, from (34), there is a $\lambda_{\text {opt }}$ which maximizes the power coefficient $C_{\text {Popt }}$ and, consequently, the power captured by the turbine $P_{\text {Topt }}$. Using (35), the required turbine speed $\omega_{\text {mopt }}$ becomes proportional to the wind speed:

$$
\omega_{m o p t}=\frac{\lambda_{o p t}}{R_{T}} v_{w}
$$

By introducing (36) in (34), the power $P_{\text {Topt }}$ can be expressed as a function of $\omega_{m}$ :

$$
P_{\text {Topt }}=\frac{1}{2} \rho \cdot S \cdot C_{P_{o p t}} \cdot v_{w}^{3}=\frac{1}{2} \rho \cdot \pi \cdot R_{T}^{5} \cdot \frac{C_{P o p t}}{\lambda_{o p t}^{3}} \cdot \omega_{m}^{3}
$$

This curve $P_{\text {Topt }}$ represents the power extracted by the turbine when operating at MPP and thus at the optimum speed $\omega_{\text {mopt }}$.

To analyze the interaction between the wind turbine and the "PMSG + diode bridge", the expressions for the power captured by the wind turbine $P_{T}\left(v_{w}, \omega_{m}\right)$ and the input power to the PMSG $P_{e m}\left(\omega_{m}, V_{d c}\right)$ must be used. On account of (1), the difference between these powers will cause a variation of the speed $\omega_{m}$ until both powers are equal at a certain speed. Although the model of the "PMSG + diode bridge" has been developed for steady-state operation, expression (1) can still be used for the transient response since the variation of the speed and voltage is much slower than the rising of the currents.

In order to show the interaction graphically, curves of $P_{T}$ at a constant wind speed $(8 \mathrm{~m} / \mathrm{s}, 10 \mathrm{~m} / \mathrm{s}$, $12 \mathrm{~m} / \mathrm{s})$ and curves of $P_{e m}$ at a constant voltage $(150 \mathrm{~V}, 218 \mathrm{~V}, 300 \mathrm{~V})$ are represented in Fig. 8 as a function of the shaft speed $\omega_{m}$. In this figure, the optimum curve $P_{\text {Topt }}\left(\omega_{m}\right)(37)$ is also plotted.

Let's consider, for example, a system that operates at a constant voltage at the diode bridge output $V_{d c}=218 \mathrm{~V}$. Then, the point at steady-state operation will be the intersection of the curve $P_{e m}$ at the constant voltage $218 \mathrm{~V}$ and the curve $P_{T}$ at the actual wind speed, that is point A for $v_{w}=12 \mathrm{~m} / \mathrm{s}$, point $\mathrm{P}$ for $v_{w}=10 \mathrm{~m} / \mathrm{s}$ and point B for $v_{w}=8 \mathrm{~m} / \mathrm{s}$. In that situation, the maximum power will only be absorbed when $v_{w}=10 \mathrm{~m} / \mathrm{s}$ but not for any other wind speed, resulting in a loss of energy.

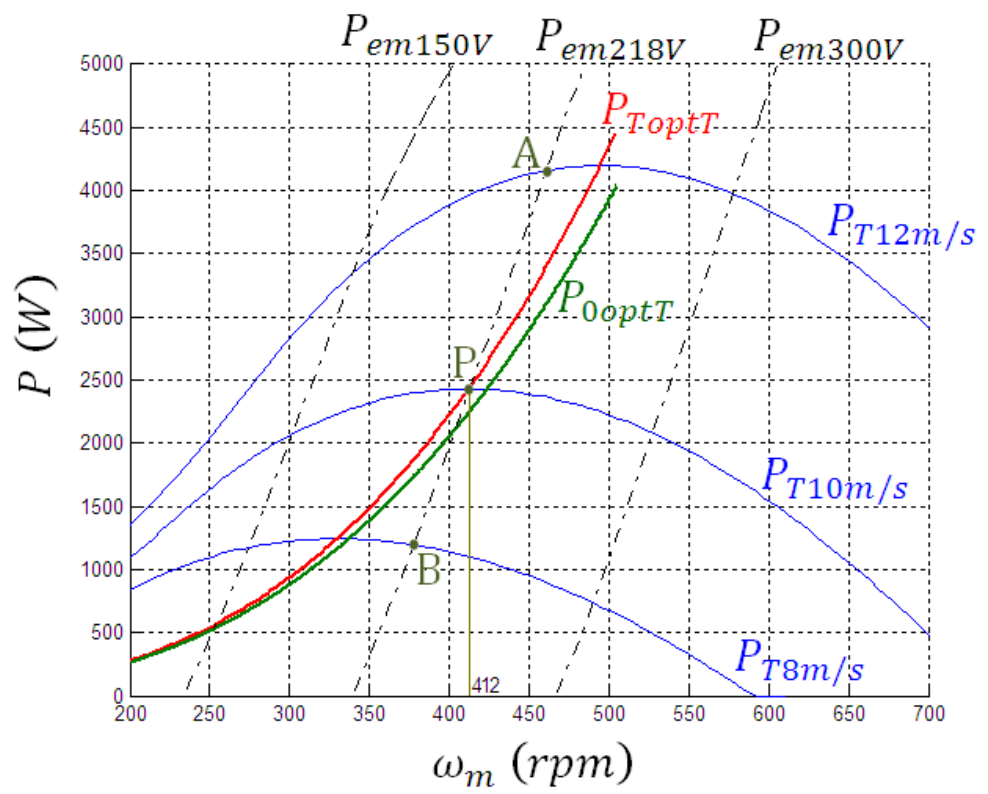

Fig. 8. Power curves for the interaction between the wind turbine and the subsystem "PMSG + diode bridge". 
Thus, in order to harvest the optimum power for any wind speed, the voltage $V_{d c}$ must be adjusted in such a way that the curve $P_{e m}\left(\omega_{m}, V_{d c}\right)$ coincides with the curve $P_{T o p t}$ at all times. In other words:

$$
P_{e m}\left(\omega_{m}, V_{d c}\right)=P_{\text {Topt }}\left(\omega_{m}\right)
$$

From (38) and using the expression (37) for $P_{\text {Topt }}\left(\omega_{m}\right)$ and the expressions (21) in CCM or (29) in DCM for $P_{e m}\left(\omega_{m}, V_{d c}\right)$, the voltage $V_{d c o p t}$ that provides maximum power for the turbine can be determined by iteration as a function of the shaft speed $\omega_{m}$. The curve obtained is represented in Fig. 9.

Hence, the curve $V_{\text {dcopt }}\left(\omega_{m}\right)$, which makes it possible to implement one of the MPPT techniques, has been theoretically determined. In that strategy the rotor speed is measured and the voltage reference $V_{d c}$ * is calculated from that speed according to the curve $V_{d c o p t}\left(\omega_{m}\right)$. In so doing, the electromagnetic power would follow the curve $P_{\text {Topt }}\left(\omega_{m}\right)$ for any rotor speed. Then, if the actual rotational speed is under the optimum speed, the power demanded by the PMSG drops below the wind turbine power and the system accelerates; if the actual rotational speed is over the optimum speed, then the power demanded goes above the wind turbine power and the system brakes (see Fig. 8). In both cases, the power evolves until it reaches maximum power. However, a mechanical sensor is required. In order to do without this sensor, the analysis must continue beyond the mechanical interaction.

To control the system from the DC side, it is necessary to obtain the power $P_{0}$ that must be imposed at the output in order to guarantee that the power $P_{e m}$ is $P_{\text {Topt }}$. This curve is called $P_{0 o p t}$ and is defined as the turbine power $P_{\text {Topt }}$ less the resistive losses. It can be easily determined using the expression for $P_{0}\left(V_{d c}, \omega_{m}\right)$ in CCM, (23), or in DCM, (30), evaluated by means of the curve $V_{\text {dcopt }}\left(\omega_{m}\right)$ shown in Fig. 9. The curve $P_{0 o p t T}$ is represented as a function of the rotor speed $\omega_{m}$ in Fig. 8.

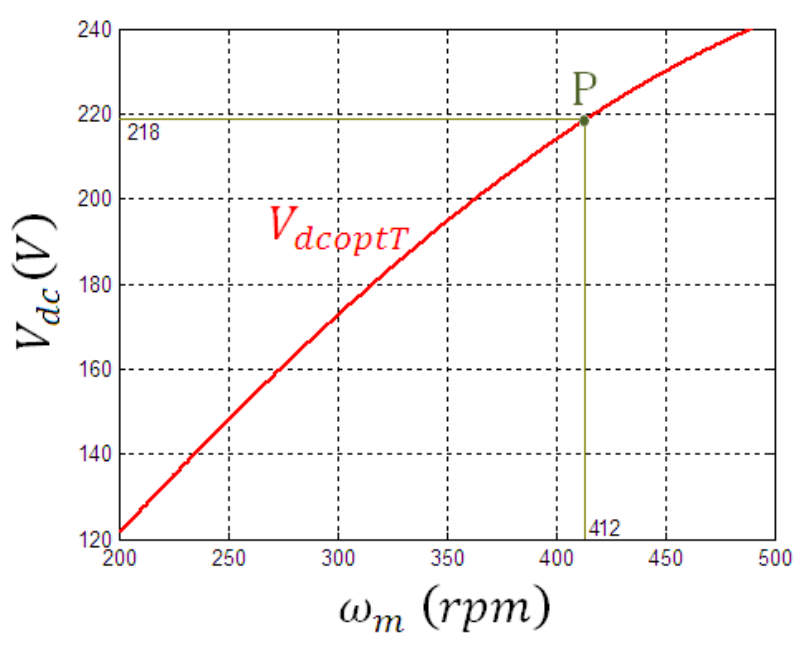

Fig. 9. Optimum curve $V_{d c o p t T}$ versus $\omega_{m}$.

\section{BEHAVIOR OF THE WHOLE SYSTEM}

Finally, the boost converter will be integrated into the whole system. Since the inductor current $I_{L}$ is controlled, the boost converter functions as a current source. Consequently, the power that enters the converter is:

$$
P_{L}=V_{d c} \cdot I_{L}
$$


To analyze the interaction between the boost converter and the rest of the system, the expressions for the power absorbed by the boost converter $P_{L}\left(V_{d c}, I_{L}\right)$ and for the diode bridge output power $P_{0}\left(\omega_{m}, V_{d c}\right)$ must be used. On account of (3), the difference between these powers will cause a variation of the voltage $V_{d c}$ until both powers are equal at a certain voltage.

In order to show the interaction graphically, curves of $P_{0}$ at a constant rotor speed $(320 \mathrm{rpm}$, $412 \mathrm{rpm}, 500 \mathrm{rpm})$ and curves of $P_{L}$ at a constant current $(5 \mathrm{~A}, 10.3 \mathrm{~A}, 15 \mathrm{~A})$ are represented in Fig. 10 as a function of voltage $V_{d c}$. Since $V_{d c}$ is the common variable, the power $P_{0 o p t}$ must also be obtained as a function of this voltage. This curve can easily be determined by evaluating $P_{0}\left(V_{d c}, \omega_{m}\right)$ (expression (23) in CCM or (30) in DCM) at the optimum points, which are defined by the optimum curve $V_{d c o p t}\left(\omega_{m}\right)$ shown in Fig. 9. In so doing, $P_{\text {oopt }}\left(V_{d c}\right)$ can now be included in Fig. 10.

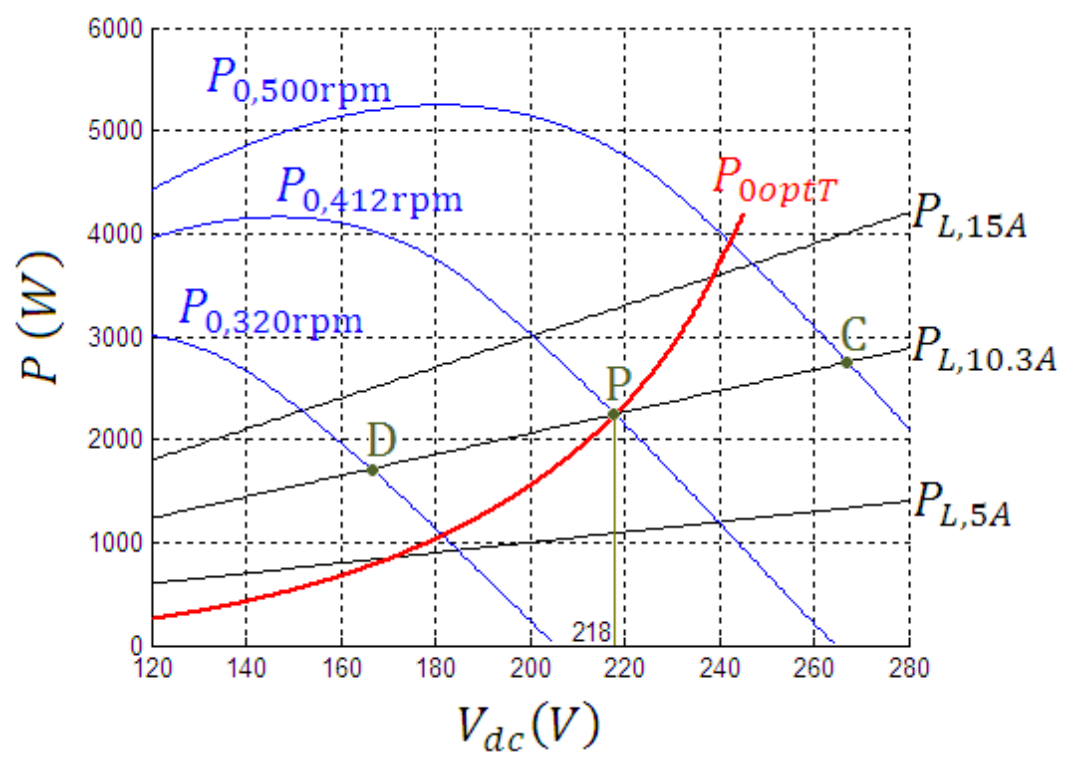

Fig. 10. Power curves for the interaction boost converter - "PMSG + diode bridge".

Let's set for example a constant current at the output of the diode bridge $I_{L}=10.3 \mathrm{~A}$. Then, the point at steady-state operation will be the intersection of the curve $P_{L}$ at the constant current $10.3 \mathrm{~A}$ and the curve $P_{0}$ for the rotor speed at that moment, that is point $\mathrm{C}$ for $\omega_{m}=500 \mathrm{rpm}$, point P for $\omega_{m}=412 \mathrm{rpm}$ and point D for $\omega_{m}=320 \mathrm{rpm}$. In that situation, the diode bridge output power $P_{0}$ will be the optimum power $P_{0 o p t}$ only when $\omega_{m}=412 \mathrm{rpm}$ but not for any other rotor speed. Likewise, the voltage will be $V_{d c o p t}$ and therefore the electromagnetic power will be $P_{\text {Topt }}$ only when $\omega_{m}=412 \mathrm{rpm}$ but not for any other rotor speed.

Thus, in order to follow those optimum curves for any rotor speed, the current $I_{L}$ must be controlled in such a way that the curve $P_{L}\left(V_{d c}, I_{L}\right)$ coincides with the curve $P_{0 o p t}$ at all times. In other words:

$$
P_{L}\left(V_{d c}, I_{L}\right)=P_{0 o p t}\left(V_{d c}\right)
$$

By means of (39), the current $I_{L o p t}$ can be determined as a function of the voltage $V_{d c}$ :

$$
I_{\text {Lopt }}=\frac{P_{0 o p t}\left(V_{d c}\right)}{V_{d c}}
$$

The curve obtained is represented in Fig. 11. 


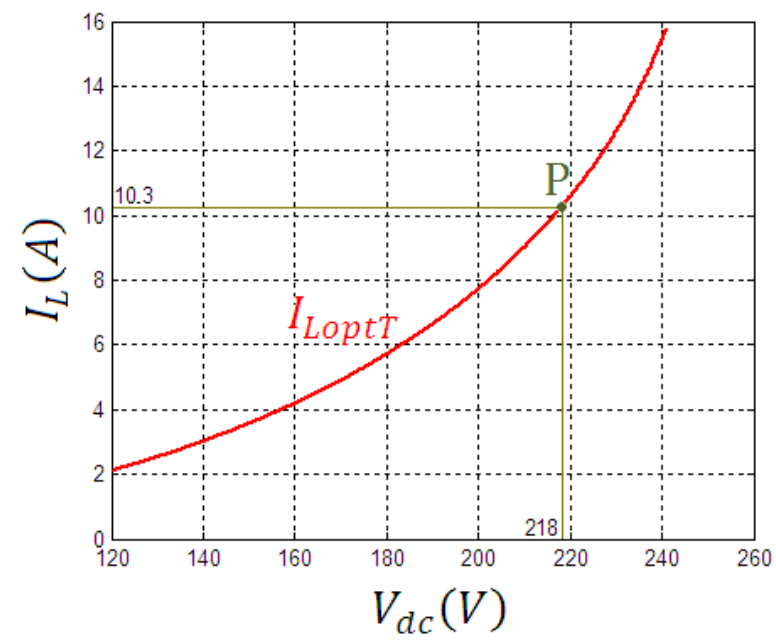

Fig. 11. Optimum curve $I_{L o p t T}$ versus $V_{d c}$.

The complete process to determine the curve $I_{L o p t}\left(V_{d c}\right)$ is summarized in Fig. 12. The optimum curve $P_{\text {Topt }}\left(\omega_{m}\right)$, which is provided by the manufacturer, and the specifications of the PMSG and the line (voltage constant $V / r p m$, number of pole pairs $p$, equivalent resistor $R$ and equivalent inductance $L$ ) are required for the calculation. By means of (38), and considering the turbine curve and the expressions for the $P_{e m}\left(\omega_{m}, V_{d c}\right)$ in CCM (21) or DCM (29), the relationship between the voltage $V_{d c}$ and the speed $\omega_{m}$ at the optimum operating points is determined. Then, the latter is used to evaluate $P_{0}\left(\omega_{m}, V_{d c}\right)$ (expression (23) in CCM and (30) in DCM) and to obtain the optimum curve $P_{0 o p t}\left(V_{d c}\right)$ as a function of $V_{d c}$. Finally, with (41), the curve $I_{L o p t}\left(V_{d c}\right)$ is calculated.

The curve $I_{\text {Lopt }}$ is static and needs to be determined only once. Then, it can be stored in a lookup table to obtain the current reference $I_{L} *$ from the measured voltage $V_{d c}$ during operation.

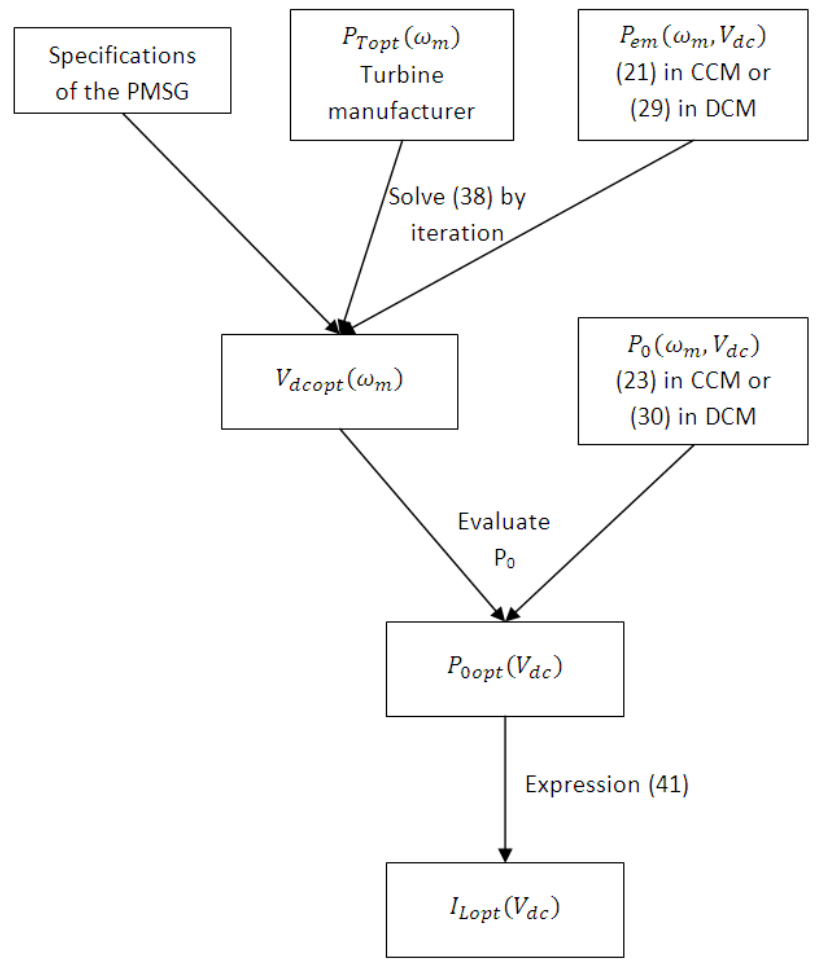

Fig. 12. Determination of the optimum curve $I_{\text {LoptT }}$. 
In so doing, the system evolves to the optimum point for any wind speed. Indeed, imposing the inductor current $I_{\text {Lopt }}$ as a function of the measured voltage $V_{d c}$ causes the power $P_{L}$ to be $P_{0 o p t}$ for any voltage. Then, if the actual voltage is under the optimum voltage for a given rotor speed, the power demanded by the boost converter drops below the diode bridge output power and the voltage increases; on the contrary, if the actual voltage is over the optimum voltage, then the power demanded goes above the output power and the voltage decreases (see Fig. 10). In both cases, the diode bridge output power $P_{0}$ changes until it reaches curve $P_{0 o p t}$. Since the voltage varies at a faster rate than the rotor speed, the diode bridge output power $P_{0}$ always gets equal to $P_{0 o p t}$. As a result, voltage $V_{d c}$ follows $V_{d c o p t}$ for any rotor speed (see Fig. 9) and the electromagnetic power $P_{e m}$ is $P_{\text {Topt }}$ at all times (see Fig. 8). This implies that the rotor speed follows the optimum speed, leading to the MPPT for any wind speed.

\section{EXPERIMENTAL RESULTS}

In this section, the system model and the MPPT control are tested. This analysis is based on the wind turbine installed at the campus of the Public University of Navarra (Pamplona, Spain), with the features shown in Table 1. This wind turbine is emulated by means of a variable-speed drive (VSD) with a permanent magnet synchronous motor (PMSM) and an inertia of $5 \mathrm{~kg} \cdot \mathrm{m}^{2}$ coupled with the mechanical shaft. The specifications of the PMSG which is connected to the shaft and of the line are provided in Table 2. The total equivalent resistance $R$ is $0.8 \Omega$ and the total equivalent inductance $L$ is $5.2 \mathrm{mH}$. The real wind turbine and the wind turbine emulator, which have the same power and very similar parameters, are shown in Fig. 13. The capacitance of $C_{d c}$ is $2 \mathrm{mF}$.

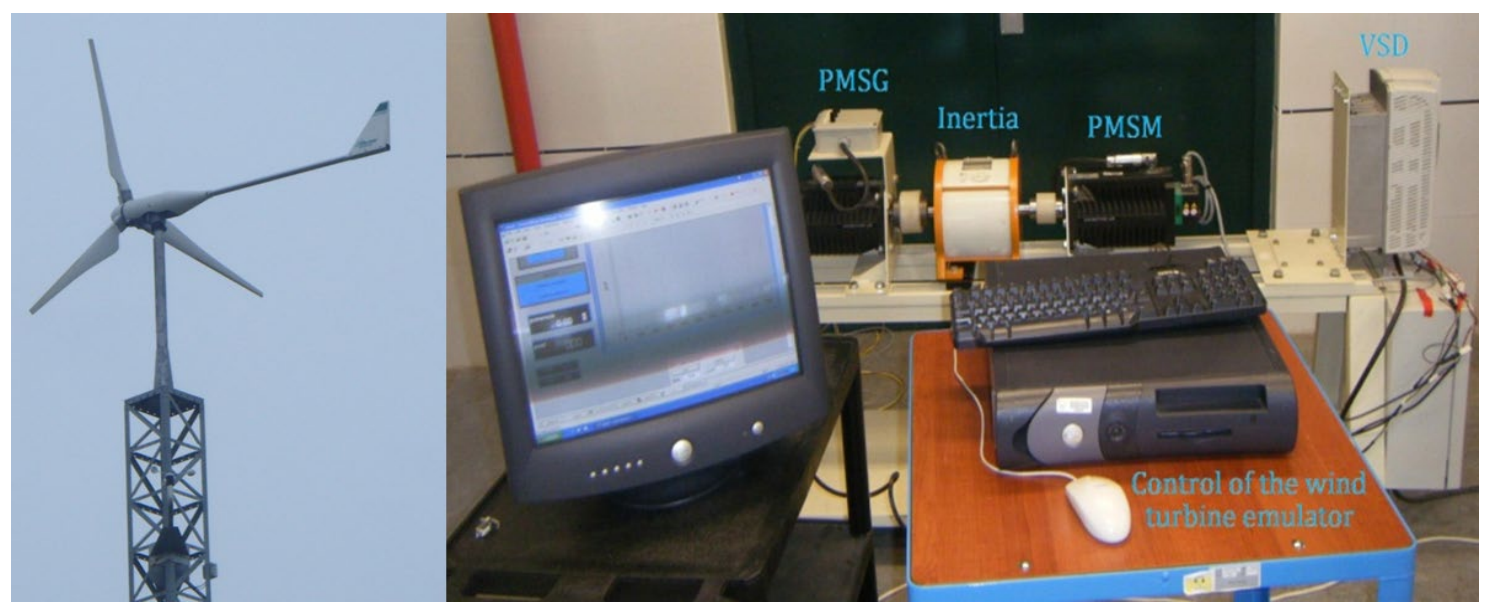

Fig. 13. Wind turbine and wind turbine emulator.

First of all, the model of the "PMSG + diode bridge" is validated. For this purpose, the theoretical curves for the output power $P_{0}$ at constant speed and voltage are compared with the experimental points obtained. The results are shown in Fig. 14. It can be seen that the experimental results are very close to the theoretical curves.

Once the model is validated, the MPPT control is implemented. The inductor current reference $I_{L}{ }^{*}$ is obtained as a function of the measured voltage $V_{d c}$ from a lookup table which stores the curve $I_{\text {Lopt }}\left(V_{d c}\right)$ of Fig. 11. This current is controlled by means of the strategy explained in [22], which is valid and robust for continuous and discontinuous inductor current. The block diagram of the MPPT control is shown in Fig. 15. In order to emulate the wind turbine, the torque reference for the VSD is calculated by a DSP as a function of the measured shaft and wind speeds according to the turbine power curves shown in Fig. 8. The wind profile, presented in Fig. 16 (a), was obtained from two anemometers located in the wind turbine tower, providing one value per second. 


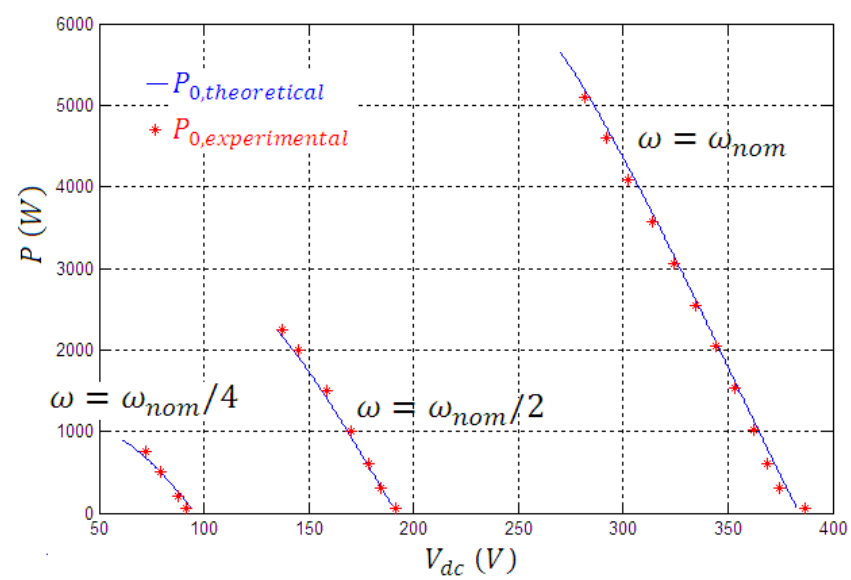

(a) Curves at constant speed

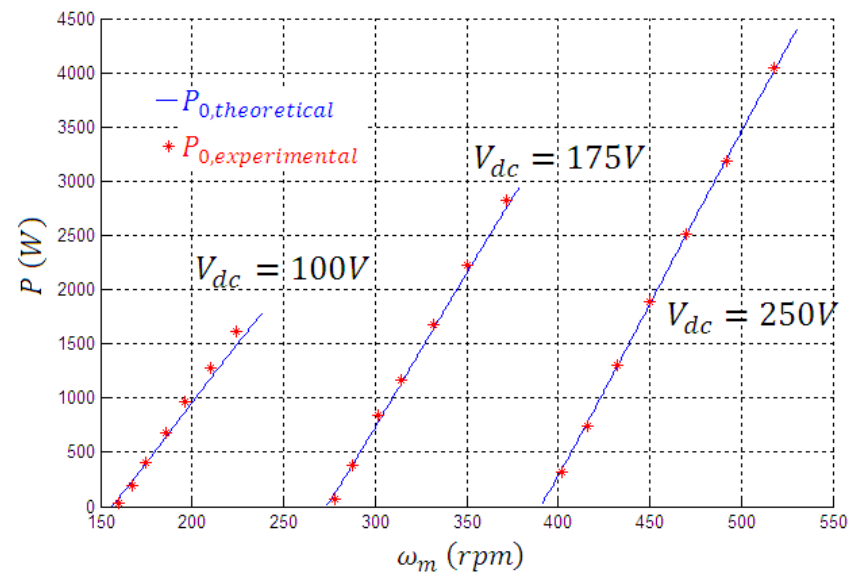

(b) Curves at constant voltage

Fig. 14. Theoretical and experimental power curves for the "PMSG + diode bridge".

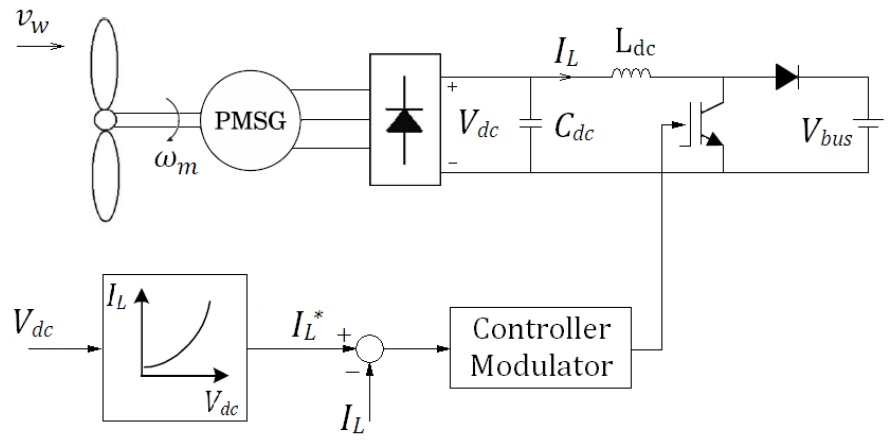

Fig. 15. Block diagram of the MPPT control.

In Fig. 16 (b), the optimum and actual speeds are shown. Although there is an expected delay caused by the inertia, it can be seen how the actual speed follows the optimum speed. Since this delay is limited as a result of the MPPT control, maximum power is achieved during the whole experiment, as shown in Fig. 16 (c). More precisely, $50.81 \mathrm{Wh}$ of the $51.14 \mathrm{Wh}$ available are extracted by the turbine in the 90 second duration of the experiment, representing an MPPT efficiency of $99.36 \%$. Other experiments have been carried out, with efficiencies varying between 99.0 and $99.5 \%$. Furthermore, in Fig. 16 (d), it can be observed how the voltage $V_{d c}$ evolves as a function of the actual speed $\omega_{m}$, actually following the optimum curve $V_{\text {dcopt }}\left(\omega_{m}\right)$ (see Figure 10). Likewise, the inductor current $I_{L}$ evolves as a function of the voltage $V_{d c}$ as 
imposed by the MPPT strategy. Thus, since $I_{L}$ evolves as a function of $V_{d c}$ and $V_{d c}$ evolves as a function of $\omega_{m}$, the dynamics of all the variables are determined by the inertia, which has two positive effects. Firstly, the output power is filtered and does not follow the wind speed variation even though maximum power is extracted. Secondly and more importantly for small wind turbines, the control is very robust since the system evolves naturally.
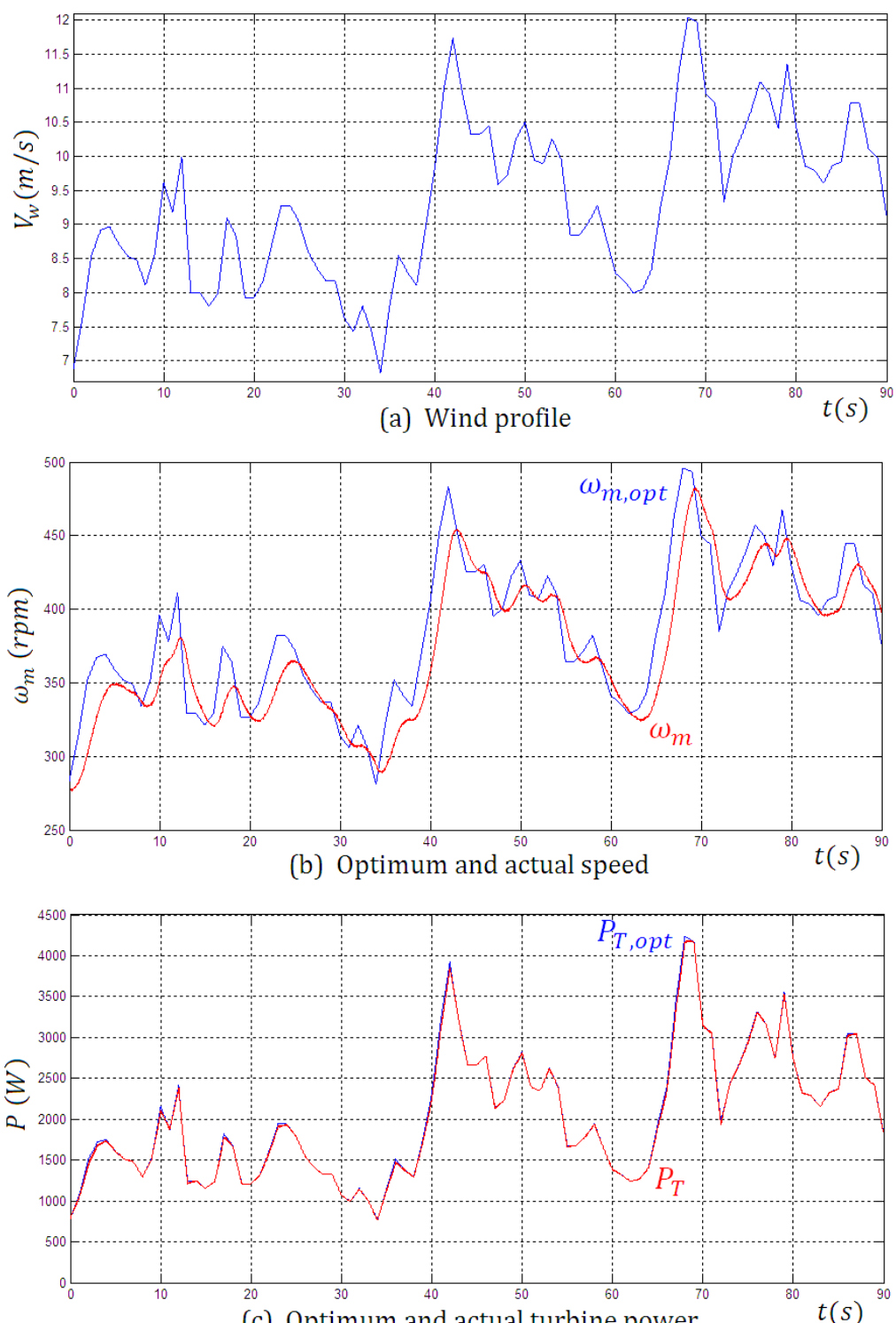

(c) Optimum and actual turbine power

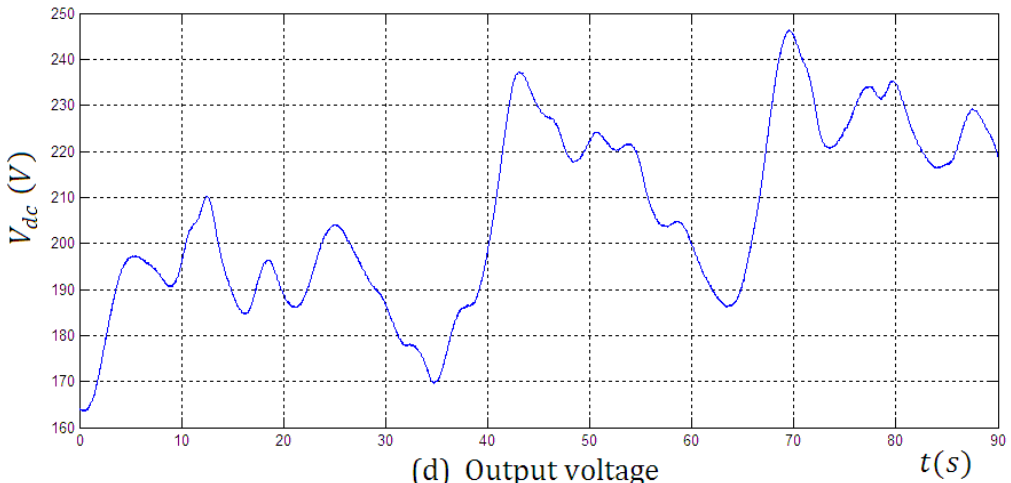

Fig. 16. Experimental results with a real wind profile. 


\section{CONCLUSION}

An accurate and complete model of a small WECS which uses a PMSG with diode bridge is developed in this paper. This study makes it possible to relate the electrical variables to the mechanical ones. In this way, the optimum curve $I_{\text {Lopt }}\left(V_{d c}\right)$ is obtained, which makes it possible to control the WECS from the DC side. Thanks to the equations of the model, the optimum curve can be calculated from commonly known system parameters, thereby avoiding the need for experimental tests or simulations. The control is very simple because only the measurements of the $V_{d c}$ voltage and of the $I_{L}$ current are required. It imposes the relationship $I_{L o p t}\left(V_{d c}\right)$ at any moment in time and, consequently, the system evolves to the optimum power for any wind speed. Firstly, the model is validated by experimental results. Then, the MPPT control is tested using a wind turbine emulator and a real wind speed profile. The results show that more than $99 \%$ of the energy available is extracted by the turbine and validate both the accuracy of the model and the robustness of the control.

\section{ACKNOWLEDGEMENT}

This work was partially funded by the Spanish Ministry of Economy and Competitiveness under Grants DPI2009-14713-C03-01 and DPI2010-21671-C02-01, by the Government of Navarra and the FEDER funds under project "Microgrids in Navarra: design and implementation" and by the Public University of Navarra.

\section{APPENDICES}

\section{A. Calculation of the current $i_{a}$ for $C C M$}

Current $i_{a}$ can be deduced from a simple RL circuit with two voltage sources, namely voltages $e_{a}$ and $v_{A N}$. To simplify, the superposition principle is used as shown in Fig. A.1. Hence, the current can be expressed as a function of currents $i_{1}$ and $i_{2}$ shown in Fig. A.1:

$$
i_{a}=i_{1}-i_{2}
$$

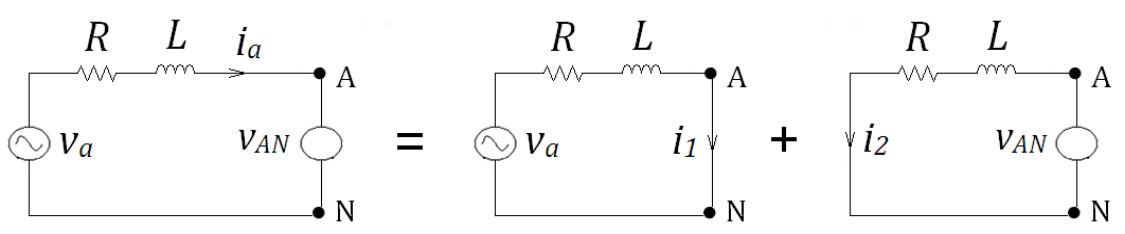

Fig. A.1. Equivalent circuit for current calculation using the superposition principle.

Because of symmetry, the current is determined for $0<\theta<\pi$, corresponding to intervals 1,2 and 3 of Fig. 4. The current initial value is set and the angle $\varphi$ will be calculated thanks to the following conditions:

$$
\begin{aligned}
& i_{a}(\theta=0)=0 \\
& i_{a}(\theta=\pi)=0
\end{aligned}
$$

From (A.1) and (A.2), the initial values of $i_{1}$ and $i_{2}$ are equal and have an unknown value of $i_{0}$. The differential equations and their solutions are expressed as follows:

$$
\omega L \frac{d i_{1}}{d \theta}+R i_{1}=\sqrt{2} E \sin (\theta+\varphi), \quad i_{1}(\theta=0)=i_{0}
$$




$$
\begin{gathered}
i_{1}(\theta)=\frac{\sqrt{2} E}{Z}\left[\sin \left(\theta+\varphi-\varphi_{Z}\right)-b \cdot e^{-\frac{\theta}{Q}}\right]+i_{0} \cdot e^{-\frac{\theta}{Q}} \\
\omega L \frac{d i_{2}}{d \theta}+R i_{2}=v_{A N}, \quad i_{2}(\theta=0)=i_{0} \\
\text { Int } 1: i_{2}(\theta)=\frac{V_{d c}}{3 R}\left(1-e^{-\frac{\theta}{Q}}\right)+i_{0} \cdot e^{-\frac{\theta}{Q}} \\
\text { Int 2: } i_{2}(\theta)=\frac{V_{d c}}{3 R}\left\lfloor 2+(-1-e 1) \cdot e^{-\frac{\theta-\pi / 3}{Q}}\right\rfloor+i_{0} \cdot e^{-\frac{\theta}{Q}} \\
\text { Int 3: } i_{2}(\theta)=\frac{V_{d c}}{3 R}\left\lfloor 1+(1-e 1-e 2) \cdot e^{-\frac{\theta-2 \pi / 3}{Q}}\right\rfloor+i_{0} \cdot e^{-\frac{\theta}{Q}}
\end{gathered}
$$

From (A.1), it can be observed in (A.5), (A.7), (A.8) and (A.9) that the initial condition $i_{0}$ is cancelled out when calculating the current $i_{a}$. Thus, in order to simplify the notation, this initial value is considered to be zero henceforth.

From (A.1) and (A.3):

$$
i_{1}(\theta=\pi)=i_{2}(\theta=\pi)
$$

Then considering expressions (16), (A.5) and (A.9) to evaluate (A.10), the lag angle $\varphi$ is determined as:

$$
\varphi=\varphi_{Z}-\sin ^{-1}\left(\frac{V_{d c}}{3 \sqrt{2} E} \cdot \frac{Z}{R} \cdot e a u x\right)
$$

The previous expressions define the phase current $i_{a}$ at any time as a function of the shaft speed $\omega_{m}$ and the capacitor voltage $V_{d c}$ at steady-state operation.

\section{B. Calculation of the current $i_{a}$ for DCM}

As in the continuous conduction mode (Fig. A.1), the current can be obtained from an RL circuit by applying the superposition principle. However, in this case, the voltage $v_{A N}$ is split into three components $\left(v_{2}, v_{3}\right.$ and $\left.v_{4}\right)$.

The three components of $v_{A N}$ are shown in Fig. B.1, where $v_{2}$ is the voltage $v_{A N}$ in the continuous conduction mode, $v_{3}$ is composed by the pieces of sinusoidal waves of the intervals 1, 3 and 5, and $v_{4}$ by the remaining waves (see also Fig. 6).

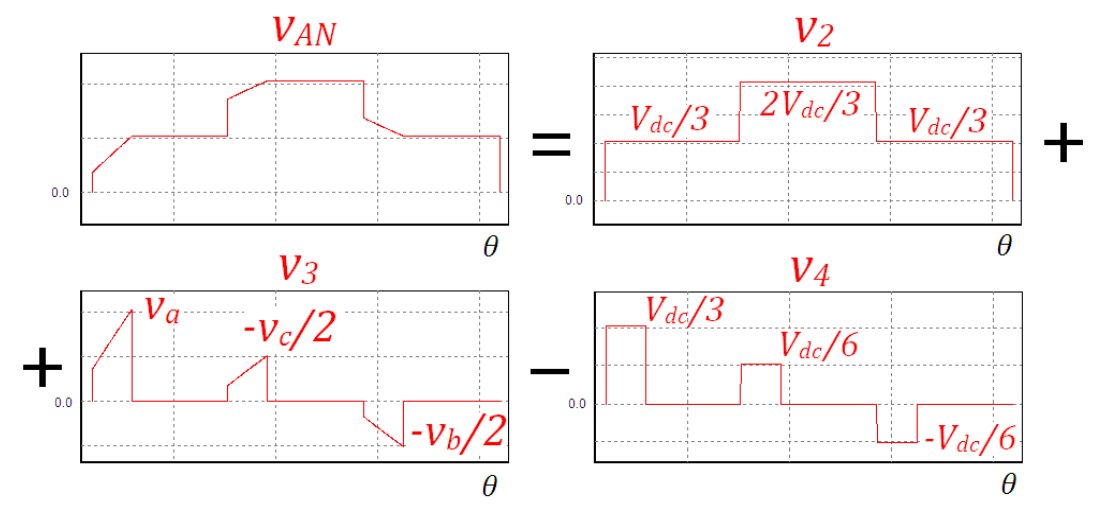

Fig. B.1. Splitting of $v_{A N}$ in DCM. 
In this way, the voltage applied to the RL circuit can be split into four different components:

$$
e_{a}-v_{A N}=e_{a}-\left(v_{2}+v_{3}-v_{4}\right)=e_{a}-v_{2}-v_{3}+v_{4}
$$

The current of the phase A can then be calculated as:

$$
i_{a}=i_{1}-i_{2}-i_{3}+i_{4}
$$

where currents $i_{1}$ and $i_{2}$ are due to $e_{a}$ and $v_{2}$ respectively, and their expressions have been calculated for the CCM (although angle $\varphi$ is not the same); currents $i_{3}$ and $i_{4}$ are due to $v_{3}$ and $v_{4}$ respectively, and are determined below. As in CCM, the initial conditions for the currents $i_{1}, i_{2}$, $i_{3}$ and $i_{4}$ can be set to zero without changing the final expression of $i_{a}$.

The differential equation for $i_{3}$ and its solution are:

$$
\begin{gathered}
\omega L \frac{d i_{3}}{d \theta}+R i_{3}=v_{3}, \quad i_{3}(\theta=0)=0 \\
\text { Int } 1: i_{3}(\theta)=\frac{\sqrt{2} E}{Z}\left[\sin \left(\theta+\varphi-\varphi_{Z}\right)-b \cdot e^{-\frac{\theta}{Q}}\right] \\
\text { Int } 2: i_{3}(\theta)=\frac{\sqrt{2} E}{Z}(a-b \cdot e \alpha) \cdot e^{-\frac{\theta-\alpha}{Q}} \\
\text { Int } 3: i_{3}(\theta)=\frac{\sqrt{2} E}{2 Z}\left[\sin \left(\theta-\frac{\pi}{3}+\varphi-\varphi_{Z}\right)+\right. \\
\left.+\left(-b+2 a \frac{e 1}{e \alpha}-2 b \cdot e 1\right) e^{-\frac{\theta-\pi / 3}{Q}}\right] \\
\text { Int } 4: i_{3}(\theta)=\frac{\sqrt{2} E}{2 Z}(a-b \cdot e \alpha+2 a \cdot e 1-2 b \cdot e 1 \cdot e \alpha) \cdot e^{-\frac{\theta-\pi / 3-\alpha}{Q}} \\
\text { Int } 5: i_{3}(\theta)=\frac{\sqrt{2} E}{2 Z}\left[-\sin \left(\theta-\frac{2 \pi}{3}+\varphi-\varphi_{Z}\right)+\right. \\
\left.+\left(b+a \frac{e 1}{e \alpha}-b \cdot e 1+2 a \frac{e 2}{e \alpha}-2 b \cdot e 2\right) e^{-\frac{\theta-2 \pi / 3}{Q}}\right] \\
\text { Int } 6: i_{3}(\theta)=\frac{\sqrt{2} E}{2 Z}(-a+b \cdot e \alpha+a \cdot e 1-b \cdot e 1 \cdot e \alpha+ \\
+2 a \cdot e 2-2 b \cdot e 2 \cdot e \alpha) e^{-\frac{\theta-2 \pi / 3-\alpha}{Q}}
\end{gathered}
$$

In the same way, for $i_{4}$ :

$$
\begin{gathered}
\omega L \frac{d i_{4}}{d \theta}+R i_{4}=v_{4}, \quad i_{4}(\theta=0)=0 \\
\text { Int } 1: i_{4}(\theta)=\frac{V_{d c}}{3 R}\left(1-e^{-\frac{\theta}{Q}}\right) \\
\text { Int } 2: i_{4}(\theta)=\frac{V_{d c}}{3 R}(1-e \alpha) e^{-\frac{\theta-\alpha}{Q}}
\end{gathered}
$$




$$
\begin{gathered}
\text { Int } 3: i_{4}(\theta)=\frac{V_{d c}}{6 R}\left[1+\left(-1+2 \frac{e 1}{e \alpha}-2 e 1\right) e^{\left.-\frac{\theta-\pi / 3}{Q}\right]}\right. \\
\text { Int } 4: i_{4}(\theta)=\frac{V_{d c}}{6 R}(1-e \alpha+2 e 1-2 e 1 \cdot e \alpha) e^{-\frac{\theta-\pi / 3-\alpha}{Q}} \\
\quad \text { Int } 5: i_{4}(\theta)=\frac{V_{d c}}{6 R}\left[-1+\left(1+\frac{e 1}{e \alpha}-e 1+\right.\right. \\
\left.\left.+2 \frac{e 2}{e \alpha}-2 e 2\right) e^{-\frac{\theta-2 \pi / 3}{Q}}\right] \\
\text { Int } 6: i_{4}(\theta)=\frac{V_{d c}}{6 R}(-1+e \alpha+e 1-e 1 \cdot e \alpha+ \\
+2 e 2-2 e 2 \cdot e \alpha) e^{-\frac{\theta-2 \pi / 3-\alpha}{Q}}
\end{gathered}
$$

Furthermore, the two angles $\alpha$ and $\varphi$ are related by the following equation (see Fig. 6):

$$
e_{a}(\theta=\alpha)=\sqrt{2} E \sin (\varphi+\alpha)=V_{d c} / 3
$$

And thus,

$$
\varphi=\sin ^{-1}\left(\frac{V_{d c}}{3 \sqrt{2} E}\right)-\alpha
$$

Then, (A.3) must also be considered to calculate $\alpha$ and $\varphi$. The Newton-Raphson method is used to determine $\alpha$ from (A.3), and (B.18) is used to determine $\varphi$. Hence, the expressions of phase current $i_{a}$ is defined at any time as a function of the shaft speed $\omega_{m}$ and the capacitor voltage $V_{d c}$ at steady-state operation.

\section{NOMENCLATURE}

$\begin{array}{ll}\alpha & \text { Retard angle in DCM } \\ \theta & \text { Electrical angle of the PMSG } \\ \lambda & \text { Tip speed ratio of the turbine } \\ \lambda_{\text {opt }} & \text { Optimum tip speed ratio of the turbine } \\ \rho & \text { Air density } \\ \varphi & \text { Lag angle } \\ \varphi_{\mathrm{Z}} & \text { Phase of the impedance } Z \\ \omega & \text { Electrical speed of the PMSG } \\ \omega_{m} & \text { Mechanical speed of the turbine and PMSG } \\ \omega_{\text {mopt }} & \text { Mechanical speed at the optimum operating points } \\ a, b, c, d & \text { Defined parameters } \\ C_{b u s} & \text { Bus capacitance } \\ C_{d c} & \text { Capacitance at the diode bridge output } \\ C_{P} & \text { Power coefficient of the turbine } \\ C_{P o p t} & \text { Optimum power coefficient of the turbine } \\ \text { D1,2,3 } & \text { Upper diodes in the diode bridge } \\ \text { D4,5,6 } & \text { Lower diodes in the diode bridge } \\ E & \text { RMS value of the induced electromotive force } \\ e 1,2,3 & \text { Defined parameters } \\ \text { e } \alpha, a u x & \text { Defined parameters }\end{array}$




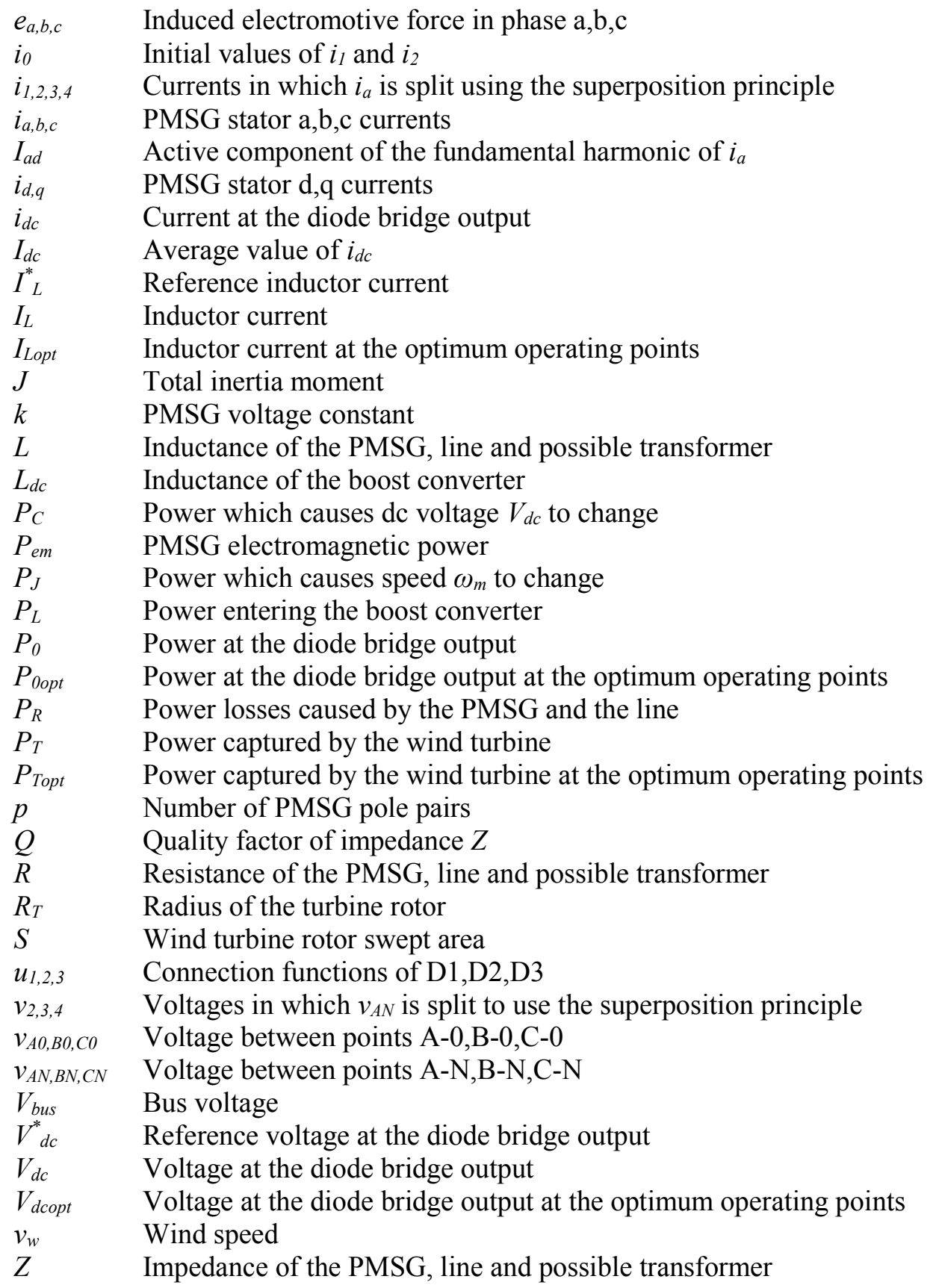

\section{References}

[1] S. Song, S. Kang, N. Hahm. Implementation and Control of Grid Connected AC-DC-AC Power Converter for Variable Speed Wind Energy Conversion System. Applied Power Electronics Conference and Exposition (APEC) 2003, 1, 154-158.

[2] I. Colak, S. Sagiroglu, M. Yesilbudak. Data mining and wind power prediction: A literature review. Renewable Energy 2012, 46, 241-247.

[3] AWEA American Wind Energy Association. AWEA Small Wind Turbine Global Market Study.

[4] N. A. Orlando, M. Liserre, V. G. Monopoli, R. A. Mastromauro, A. Dell'Aquila. Comparison of power converter topologies for permanent magnet small wind turbine system. International Symposium on Industrial Electronics (ISIE) 2008, 2359-2364.

[5] J. A. Baroudi, V. Dinavahi, A. M. Knight. A review of power converter topologies for wind generators. Renewable Energy 2007, 32 (14), 2369-2385. 
[6] T. Senjyu, S. Tamaki, E. Muhando, N. Urasaki, H. Kinjo, T. Funabashi, H. Fujita, H. Sekine. Wind velocity and rotor position sensorless maximum power point tracking control for wind generation system. Renewable Energy 2006, 31 (11), 1764-1775.

[7] R. Esmaili, L. Xu, D.K. Nichols. A New Control Method of Permanent Magnet Generator for Maximum Power Tracking in Wind Turbine Application. Power Engineering Society General Meeting 2005, 3, 2090-2095.

[8] S. Jiao, G. Hunter, V. Ramsden, D. Patterson. Control System Design for a 20kW Wind Turbine Generator with a Boost Converter and Battery Bank Load. Power Electronics Specialists Conference (PESC) 2001, 4, 2203-2206.

[9] M. Kesraoui, N. Korichi, A. Belkadi. Maximum power point tracker of wind energy conversion system. Renewable Energy 2010, 36 (10), 2655-2662.

[10] H. Wang, C. Nayar, J. Su, M. Ding. Control and Interfacing of a Grid-Connected SmallScale Wind Turbine Generator. IEEE Transactions on Energy Conversion 2011, 26 (2), 428-434.

[11] N. Yamamura, M. Ishida, T. Hori. A Simple Wind Power Generating System with Permanent Magnet Type Synchronous Generator. Power Electronics and Drive Systems (PEDS) 1999, 2, 849-854.

[12] E. Koutroulis, K. Kalaitzakis. Design of a Maximum Power Tracking System for WindEnergy-Conversion Applications. IEEE Transactions on Industrial Electronics 2006, 53 (2), 486-494.

[13] S. M. R. Kazmi, H. Goto, H. J. Guo, O. Ichinokura. A Novel Algorithm for Fast and Efficient Speed Sensorless Maximum Power Point Tracking in Wind Energy Conversion Systems. IEEE Transactions on Industrial Electronics, 58 (1), 29-36.

[14] M. Narayana, G. A. Putrus, M. Jovanovic, P. S. Leung, S. McDonald. Generic maximum power point tracking controller for small-scale wind turbines. Renewable Energy 2012, 44, $72-79$.

[15] M. E. Haque, M. Negnevitsky, K. M. Muttaqi. A Novel Control Strategy for a VariableSpeed Wind Turbine with a Permanent-Magnet Synchronous Generator. IEEE Transactions on Industry Applications 2010, 46 (1), 331-339.

[16] V. Lazarov, D. Roye, D. Spirov, Z. Zarkov. New Control Strategy for Variable Speed Wind Turbine with DC-DC converters. Power Electronics and Motion Control Conference (PEMC) 2010, T12-120 - T12-124.

[17] S. M. Dehghan, M. Mohamadian, A. Y. Varjani. A New Variable-Speed Wind Energy Conversion System Using Permanent-Magnet Synchronous Generator and Z-Source Inverter. IEEE Transactions on Energy Conversion 2009, 24 (3), 714-724.

[18] K. Tan, S. Islam. Optimum Control Strategies in Energy Conversion of PMSG Wind Turbine System without Mechanical Sensors. IEEE Transactions on Energy Conversion 2004, 19 (2), 392-399.

[19] I. Serban, C. Marinescu. A sensorless control method for variable-speed small wind turbines. Renewable Energy 2012, 43, 256-266.

[20] P. Pejovic, J. W. Kolar. An Analysis of three-phase rectifiers with constant voltage loads. Circuits and Systems for Communications (ECCSC) 2010, 119-126.

[21] V. Caliskan, D. J. Perreault, T. M. Jahns, J. G. Kassakian. Analysis of three-phase rectifiers with constant-voltage loads. IEEE Transactions on Circuits and Systems I: Fundamental Theory and Applications 2003, 50 (9), 1220-1225.

[22] K. Gussemé, D. M. Van de Sype, A. P. M. Van den Bossche, J. A. Melkebeek. Digitally Controlled Boost Power-Factor-Correction Converters Operating in both Continuous and Discontinuous Conduction Mode. IEEE Transactions on Industrial Electronics 2005, 52 (1), 88-97. 